Universidad de Lima

Facultad de Derecho

Carrera de Derecho

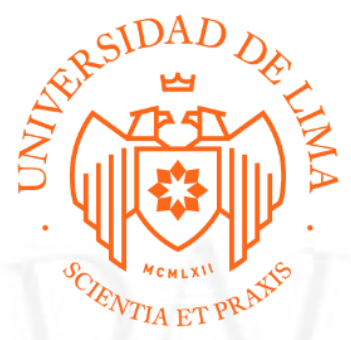

\title{
EXPEDIENTES CIVIL: "DIVORCIO POR CAUSAL" Y PENAL: "VIOLACIÓN SEXUAL AL MENOR DE EDAD"
}

Trabajo de suficiencia profesional para optar el Título Profesional de Abogado

\section{Cronwel Bazán Denegri}

Código 20100126

Lima - Perú

abril de 2019 


\section{EXPEDIENTES CIVIL: "DIVORCIO POR CAUSAL"}

Materia: Divorcio por causal

$N^{o}$ de Expediente: 00940-2010-0801-JR-FC-02

\section{RESUMEN}

Se trata de una demanda de divorcio por causal de separación de hecho que presenta el interesado contra la demandada, a fin que se disuelva el vínculo matrimonial celebrado entre ambos en marzo de 1986 fuera de Lima.

\section{PENAL: "VIOLACIÓN SEXUAL AL MENOR DE EDAD" \\ Materia: Violación sexual de menor de edad $\mathrm{N}^{\mathrm{o}}$ de Expediente: 0011-2012-0-SP--FC-02 RESUMEN}

Se trata de un expediente en el que una persona, padre de una menor de edad, interpone denuncia verbal ante la $2^{\mathrm{a}}$. Fiscalía Provincial Civil y Familiar de Cañete por cuanto el denunciado habría cometido delito de violación sexual contra la referida menor. 